\title{
Bioorganometallic Chemistry
}

\section{P701}

\section{Dinuclear iron-nickel complexes modeling the active} site of [NiFe] hydrogenase

Zilong Li, Soichiro Tanino, Kazunari Yasumura, Katsuaki Kuge, Masaru Ando, Yasuhiro Ohki, Kazuyuki Tatsumi

Graduate School of Science and Research Center for Material

Science, Nagoya University, Nagoya 464-8602, Japan.

Li zilong@yahoo.com.cn

The $[\mathrm{NiFe}]$ hydrogenase catalyzes the production and uptake of hydrogen molecule under mild conditions. Its active site consists of an "organometallic" $(\mathrm{CN})_{2}(\mathrm{CO}) \mathrm{Fe}-\mathrm{Ni}$ complex supported by four cysteinyl thiolate ligands. Aiming to synthesize models of the active site, we have recently developed two synthetic approaches [1-3]. One is to use a readily accessible iron carbonyl complex $\mathrm{FeBr}_{2}(\mathrm{CO})_{4},[1]$ and the other is to use an $\mathrm{Fe}$ (II) complex carrying both carbonyl and cyanide ligands, $\left[\mathrm{Fe}(\mathrm{CO})_{3}(\mathrm{CN})_{2} \mathrm{Br}\right]^{-},[2,3]$ for the reactions with thiolates and nickel compounds. These reactions led to isolation of a series of thiolate-bridged dinuclear Fe-Ni complexes as shown below, which serve as good structural models for the active site of [NiFe] hydrogenase.
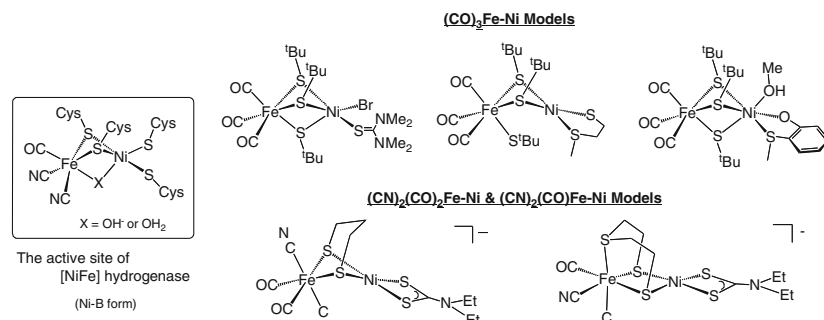

$(\mathrm{CN})_{2}(\mathrm{CO})_{2} \mathrm{Fe}-\mathrm{Ni} \&\left(\mathrm{CN}_{2}\right)_{2}(\mathrm{CO}) \mathrm{Fe}-\mathrm{Ni}$ Models
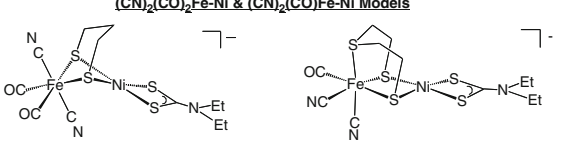

References

1. Li Y, Ohki Y, Tatsumi K (2005) J Am Chem Soc 127:8950

2. Ohki Y, Yasumura K, Kuge K, Tanino S, Ando M, Li Z, Tatsumi K (2008) Proc Natl Acad Sci USA 105:7652

3. Tanino S, Li Z, Ohki Y, Tatsumi K (2009) Inorg Chem 48 (in press)

\section{P702}

Enhanced and recycled catalysis of a Vitamin $B_{12}$ inspired catalyst in ionic liquid

Hisashi Shimakoshi, Naoya Kabashima, Keishiro Tahara, Yoshio Hisaeda

Department of Chemistry and Biochemistry, Grad. Sch. Eng,

Kyushu University, Fukuoka 819-0395, Japan.

shimakoshi@mail.cstm.kyushu-u.ac.jp

Cobalamin-dependent enzymes catalyze various molecular transformations that are of particular interest from the viewpoint of biological chemistry as well as organometallic and catalytic chemistry $[1,2]$. So we tried to construct a $B_{12}$ dependent molecular transformation system utilizing the ionic liquid as reaction media [3, 4]. Immobilization of a catalyst on the supports is a desirable approach for establishment of "Green Chemistry" since the catalyst is easily separated from the reaction medium and reused. Ionic liquids have various advantages as a reaction medium because of the their low melting point, negligible vapor pressure, non-flammability, and good solubility for many organic compounds. Therefore, dissolving the $\mathrm{B}_{12}$ catalyst in ionic liquid and recycled use of the solution is promising approach in this field. Here, we disclose effective and eco-friendly technique for the dechlorination of organic halides in the ionic liquid. The enhanced reactivity as well as the recyclability of the $B_{12}$ catalyst in ionic liquid makes the present system more efficient for the development of green technologies.

Natural Vitamin $B_{12}$ vs. Modified Vitamin $B_{12}$

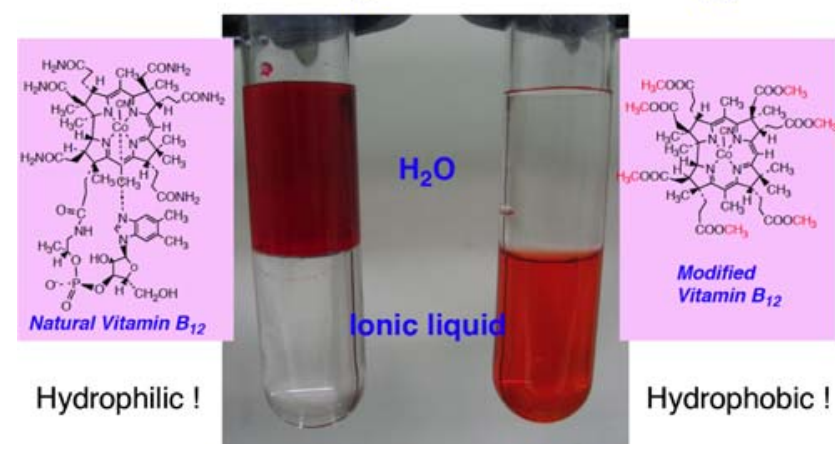

\section{References}

1. Kräutler B, Arigoni D, Golding BT (eds) (1998) Vitamin $B_{12}$ and $\mathrm{B}_{12}$-proteins, Wiley-VCH, New York

2. Banerjee R (ed) (1999) Chemistry and biochemistry of $B_{12}$, WileyInterscience, New York

3. Shimakoshi H, Hisaeda Y et al (2005) Chem Lett 34:1096-1097

4. Shimakoshi H, Hisaeda Y et al (2007) Chem Commun 1653-1655

\section{P703}

Synthesis and characterization of vitamin $B_{12}$ derivative catalyst having $R u(b p y)_{3}$ unit as a photosensitizer Jun-ichi Aoki, Hisashi Shimakoshi, Masaki Abe, Yoshio Hisaeda Department of Chemistry and Biochemistry, Grad. Sch. Eng, Kyushu University, Fukuoka 819-0395, Japan. j-aoki-

j@ms.hisaeda.cstm.kyushu-u.ac.jp

Vitamin $B_{12}$-dependent enzymes catalyze various reactions such as methyl transfer, isomerization and dehalogenation. Recently, ecofriendly catalyst system has been focused in the world. $\mathrm{Ru}(\mathrm{bpy})_{3}$ acts as a photosensitizer and has strong absorption band in visible region 
[1]. In this study, we conjugated hydrophobic vitamin $\mathrm{B}_{12}$ and $\mathrm{Ru}(\mathrm{bpy})_{3}$ by covalent bond at the $\mathrm{C} 10$ position of the corrin ring. This complex is expected to catalyze $\mathrm{B}_{12}$-mimetic reaction under irradiation with visible light.
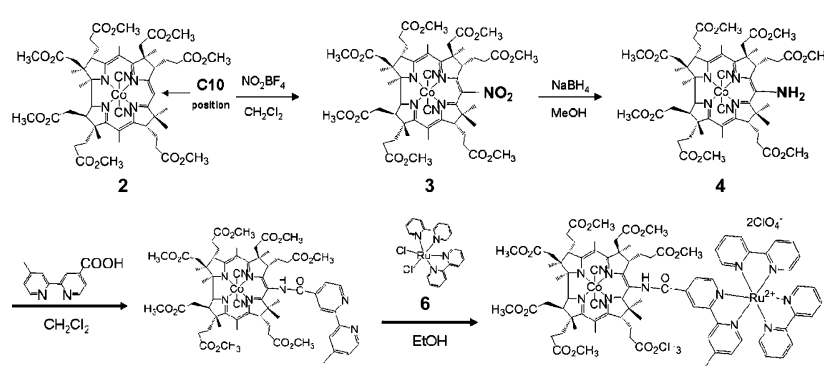

5
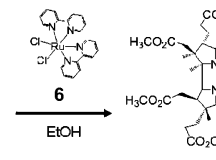

$\mathrm{CO}_{2} \mathrm{CH}_{3} \mathrm{CO}_{2} \mathrm{CH}_{3}$

$2 \mathrm{COO}_{4}$
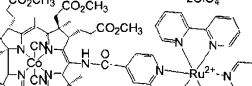

1

Hydrophobic vitamin $\mathrm{B}_{12}$ complexes 2, 3 and $\mathbf{4}$ were synthesized by previously reported methods [2]. Compound 4 and $4^{\prime}$-methyl-2,2'bipyridine-4-carboxylic acid was connected with amide bond. Refluxing a mixture of $\mathbf{5}$ and $\mathbf{6}$ in EtOH afford compound 1. In this study, we will report the synthesis and photophysical properties of vitamin $\mathrm{B}_{12}$ inspired catalyst $\mathbf{1}$.

\section{References}

1. Shimakoshi H, Tokunaga M, Baba T, Hisaeda Y (2004) Chem Commun 1806-1807

2. Shimakoshi H, Inaoka T, Hisaeda Y (2003) Tetrahedron Lett 44:6421-6424

\section{P704}

\section{Synthesis and biological properties of carboxylic acid} analogues of ferrocifens

Anne Vessieres, Pascal Pigeon, Anh Nguyen, Siden Top, Marie-Aude Plamont, Elizabeth A. Hillard,

\section{Huche, Gérard Jaouen}

Ecole Nationale Superieure de Chimie de Paris, Laboratoire Charles Friedel, UMR CNRS 7223, 11 rue P. et M. Curie, 75231 Paris Cedex 05, France. vessieres@enscp.fr

We have previously shown that $\mathrm{OH}$-ferrocifens, the ferrocenyl derivatives of $\mathrm{OH}$-tamoxifen, display the unique property of being toxic on both hormone dependent (MCF-7) and independent (MDAMB-231) breast cancer cells [1]. On the other hand, it has been published that 1, a carboxylic acid analogue of OH-tamoxifen, exhibits a strong antiproliferative effect on MCF-7 cells [2]. This prompted us to test if the substitution of the phenyl ring of $\mathbf{1}$ by a ferrocenyl unit and the change in chain length leading to compounds 3-5, enhance this antiproliferative effect.

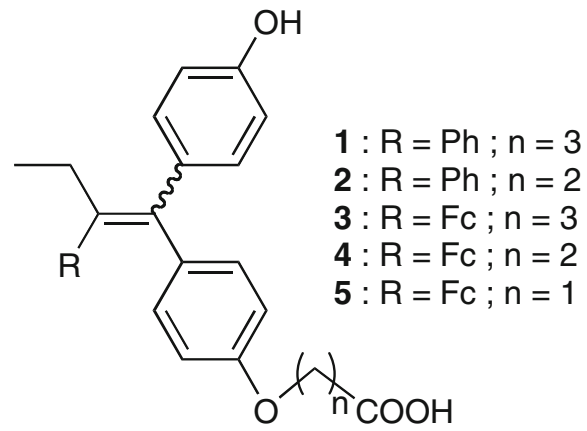

Compounds 2 and $\mathbf{4}(n=2)$ were obtained by 1,4 addition of ethyl acrylate on the corresponding di-phenols, while $\mathbf{1}, \mathbf{3}$ and $\mathbf{5}(n=1$ or 3 ) were prepared from a Williamson ether synthesis reaction.

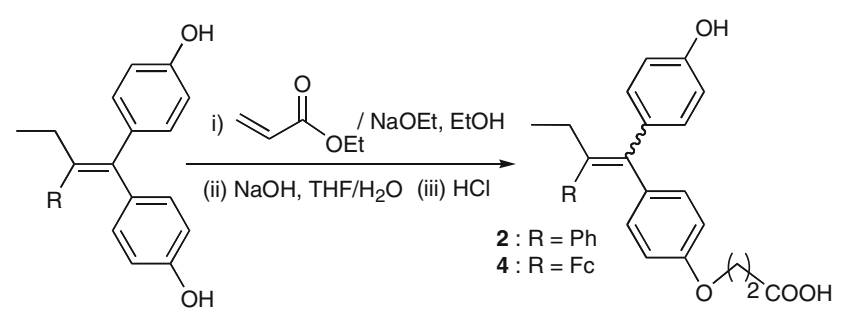

Study of the antiproliferative effect of 1-5 shows that the phenyl derivatives exhibit almost the same effect on both cell lines $\left(\mathrm{IC}_{50} \approx 10 \mu \mathrm{M}\right)$, while the $\mathrm{Fc}$ derivatives are more effective on MDA-MB-231 than on MCF-7 cells. Complex 4 is the most cytotoxic molecule of the series $\left(\mathrm{IC}_{50}=0.6 \mu \mathrm{M}\right.$ on MDA-MB-231 and $5 \mu \mathrm{M}$ on MCF-7),

\section{References}

1. Top S et al (2003) Chem Eur J 9:5223-5236

2. Kraft KS et al (1999) J Med Chem 42:3126-3133

\section{P705}

\section{Tris(pyrazolyl)borates as versatile ligands} in the synthesis of bioorganometallic compounds Johannes Zagermann, Matthew C. Kuchta, Klaus Merz, Nils Metzler-Nolte

Fakultät für Chemie und Biochemie, Ruhr-Universität Bochum, Universitätsstraße 150, 44801 Bochum, Germany.

Johannes.Zagermann@ rub.de

While cyclopentadienyl (Cp) containing compounds such as ferrocene have found various applications in bioorganometallic chemistry, little work is found concerning analogue compounds containing Cp surrogates. We have been interested in exploiting the rich coordination chemistry of tris(pyrazolyl)borate (Tp) ligands for the synthesis of bioconjugates with possible applications in biomedical, electrochemical or spectroscopical studies.
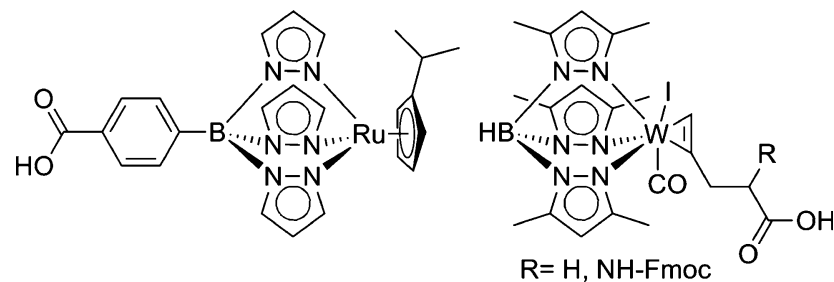

We describe the synthesis and characterization of the first mixed ligand $(\mathrm{Cp} / \mathrm{Tp})$ ruthenium sandwich compound incorporating a carboxylic acid functionalized $\mathrm{Tp}$ ligand and its application in the formation of peptide bioconjugates. More recently, we utilized iodocarbonyltungsten complexes containing a regular Tp ligand to label peptides via $\eta^{2}$-coordinated alkyne ligands including the unusual amino acid propargylglycine.

\section{References}

1. Zagermann J, Kuchta MC, Merz K, Metzler-Nolte N (2008) J Organomet Chem. doi:10.1016/j.jorganchem.2008.09.23 (in press) 


\section{P706}

Synthesis, characterization, anti-oxidant and anti-cancer property of some phenolic hydrazone derivatives

Nooraziah M. Lair ${ }^{1}$, Hapipah M. Ali ${ }^{1}$, Habsah A. Kadir ${ }^{2}$, Daniel Z.H. Wong' ${ }^{2}$, Wong Y. Hsiung ${ }^{2}$, Mahmood A. Abdulla ${ }^{3}$

${ }^{1}$ Department of Chemistry, Faculty of Science, University of Malaya, 50603 Kuala Lumpur, Malaysia.

${ }^{2}$ Institute of Biological Science, Faculty of Science,

University of Malaya, 50603 Kuala Lumpur, Malaysia.

${ }^{3}$ Department of Molecular Medicine, Faculty of Medicine,

University of Malaya, 50603 Kuala Lumpur, Malaysia.

Malaysianooraziah39@perdana.um.edu.my

Antioxidants are chemical compounds which can donate an electron to a free radical and convert it to a harmless molecule. In our bodies, antioxidants protect us from free radicals and prevent diseases including coronary heart disease, cancer and cataracts. Phenolic compounds and their derivatives have been known for their potential antioxidant and anti cancer activities. The phenolic hydrazones and their derivatives were synthesized by condensing phenolic hydrazide and carboxaldehydes. These phenolic hydrazones had coordinated to metals such $\mathrm{Zn}(\mathrm{II})$ and $\mathrm{Cu}(\mathrm{II})$, their antioxidant and anti cancer property were also determined. The structure of ligands and complexes were elucidated by using spectroscopic data such as infra-red, ${ }^{1} \mathrm{H}$ and ${ }^{13} \mathrm{C}$ NMR, UV-visible, thermogravity element analysis and $\mathrm{X}$ ray crystallographic techniques. Anti-oxidant testing for the compounds were carried out by using free radical scavenging activity (DPPH assay). Anti-cancer testing was done on several types of cancer cells such as Caski Cervical Epidermoid Carcinoma, HCT Colorectal Carcinoma, KB Mouth Epidermal Carcinoma and MCF 7 Normal Breast Adenocarcinoma via in vitro.

\section{References}

1. Boudet AM (2007) Phytochemistry 68:2722-2735

2. Vijaya Raj KK, Narayana B, Ashalatha BV, Suchetha KN, Sarojini BK (2007) Eur J Med Chem 42(3):425-429

\section{P707}

Anti-cancer activity of indole Schiff base compounds and metal complexes

Nazzatush Shimar Jamaludin ${ }^{1}$, Hapipah Mohd. Ali ${ }^{1}$, Mahmood Ameen Abdulla ${ }^{3}$, Daniel Wong Zin $\mathrm{Hua}^{2}$, Wong Yau Hsiung ${ }^{2}$, Habsah Abdul Kadir ${ }^{2}$

${ }^{1}$ Department of Chemistry,

${ }^{2}$ Institute of Biological Sciences; Faculty of Science,

${ }^{3}$ Department of Molecular Medicine; Faculty of Medicine, University of Malaya, 50603 Kuala Lumpur, Malaysia.nazshija@yahoo.com Schiff base compounds of indole derivatives and metal complexes were synthesized for the purpose of anti-cancer properties. Indole was chosen for the study since it possessed good activities in most biological purposes. The test was carried out on several cancer cell lines such as HCT 116 Colorectal Carcinoma, MDA-MB-435 Estrogen Receptor Independent Breast Adenocarcinoma, KB Mouth Epidermal Carcinoma and MCF-7 Normal Breast Adenocarcinoma. Some compounds especially compounds with chlorine and bromine was found to be potent compounds on cancer cells with concentration less than $20 \mu \mathrm{g} / \mathrm{ml}$. Acute toxicity test had been carried out in vivo and it showed no sign of abnormalities or death within $24 \mathrm{~h}$. Further observation was done and the mice were found to be alive and active.

\section{References}

1. Sinha D, Tiwari AK, Singh S, Shukla G, Mishra P, Chandra H, Mishra AK (2007) Eur J Med Chem 1-6

2. Zhong X, Wei HL, Liu WS, Wang DQ, Wang X (2007) Bioorg Med Chem Lett 17:3774-3777

3. Singh K, Barwa MS, Tyagi P ( 2007) Eur J Med Chem 42:394402

\section{P708}

Arsenic detoxification: a new approach for transformation of inorganic arsenic into arsenobetaine mediated by $\mathrm{S}$-amino acids and vitamin $B_{12}$ under mild aqueous conditions Koichiro Nakamura

R \& D Department, Nippon Sheet Glass Co., Ltd., Chitose-cho 2, Yokkaichi, Mie 510-0051, Japan. KoichiroNakamura@mail.nsg.co.jp The toxicity of arsenic compounds is markedly dependent on their chemical structure. In particular, arsenobetaine $\left[\mathrm{AB} ; \mathrm{Me}_{3} \mathrm{As}^{+}\right.$ $\mathrm{CH}_{2} \mathrm{CO}_{2}^{-}$; (trimethyl arsonio) acetate] has a low toxicity $\left(\mathrm{LD}_{50}\right.$, $10 \mathrm{~g} / \mathrm{kg}$, mice oral) and is found in high levels in fishery products. The acute toxicity of $\mathrm{AB}$ is approximately one three-hundredth of that of arsenic trioxide [iAs(III); Arsenite; $\mathrm{As}_{2} \mathrm{O}_{3} ; \mathrm{LD}_{50}, 0.03 \mathrm{~g} / \mathrm{kg}$, mice oral]. Recently a new two-step syntetic pathway for a transformation of arsenic trioxide into $\mathrm{AB}$ has been proposed and successfully demonstrated [1-2]. It ivolves treatment of iAs(III) with methylcobalamin in the presence of glutathione (GSH) to give trimethylarsine oxide (TMAO) with a high selectivity and a high conversion rate [1] followed by subsequent treatment of TMAO with iodoacetic acid in the presence of GSH to give arsenobetaine with a high yield [2]. Thus, a safe and environmentally-friendly process using biomaterials such as amino acides and vitamin $B_{12}$, conveting toxic inoganic arsenic into non-toxic arsenibetaine, is successfully confirmed $[3,4]$.

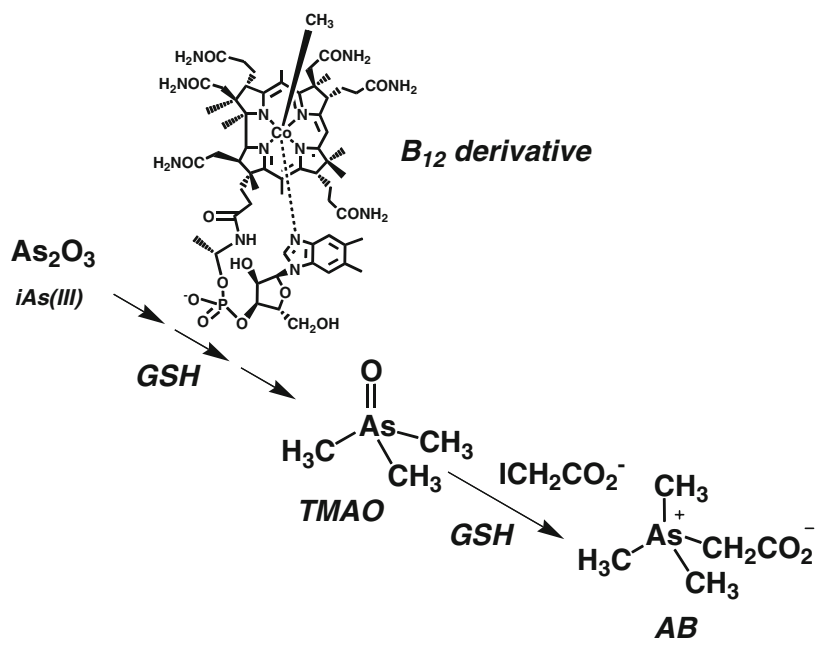

References

1. Nakamura K, Hishinuma A, Kamiya S WO/2008/012950.

2. Nakamura K, Hishinuma A, Kamiya S WO/2008/065750.

3. Nakamura K et al (2009) Chem Commun 41:5122-5124 (2008)

4. Nakamura K et al (2009) J Organometal Chem 694:916-921 


\section{P709}

Fluorescent sensors on rhodamine B basis: building block concept for versatile live cell applications and ensemble measurements

Birgit M. B. Thaler, Radoslaw M. Kierat, Roland Krämer Department of Inorganic Chemistry, University of Heidelberg, Germany, Im Neuenheimer Feld 270, 69120 Heidelberg, Germany. birgit.thaler@aci.uni-heidelberg.de

Sensors are of vital interest to chemistry, biology and medicine alike. Easy access to a versatile sensor system is achieved by using a building block concept (Fig. 1). Applying this concept we developed a redox state sensor with tuneable oxidation potentials for live cell applications (1, Fig. 2a) [1]. Different potentials are accessible by varying the quinone moiety. Altering the "switch" to metal chelating moieties metal ion sensors and a remote sensor for copper centered reactions were generated, thus enabling e.g. detection of chances in the coordination sphere of $\mathrm{Cu}^{2+}(2, \mathrm{Fig} .2 \mathrm{~b})$ [2].
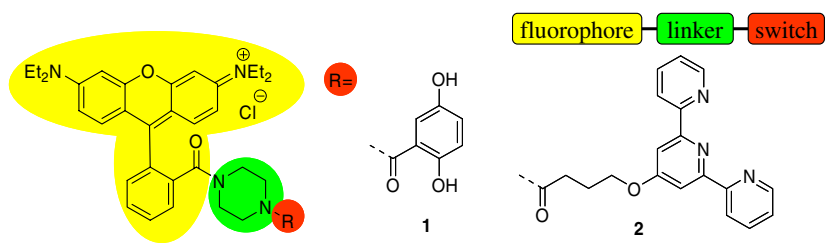

Fig. 1 Building block concept and structures of sensors
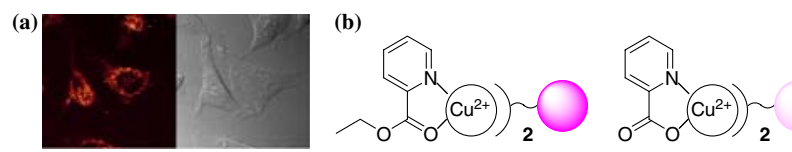

Fig. 2 a HeLa cells incubated with $1\left(7.5 \mu \mathrm{M}, 30 \mathrm{~min}, 37^{\circ} \mathrm{C}\right)$. b Change of fluorescence of $\mathbf{2}$ depending on coordination sphere of $\mathrm{Cu}^{2+}$

\section{References}

1. Kierat RM, Thaler BMB, Krämer R (2009) Bioorg Med Chem Lett (accepted)

2. Thaler BMB, Kierat RM, Krämer R (2009) (in preparation)

\section{P710}

\section{A Theoretical study on the oxidation potential of metal-binding peptides: implication}

in the neurotoxicity of $\beta$-amyloid $(A \beta)$ peptide

Min-Huei Huang ${ }^{1}$, Ren-jie Lin ${ }^{1}$, Soomin Jang ${ }^{2}$, Chen-chang Wu ${ }^{1}$, Feng-Yin $\mathbf{L i}^{\mathbf{1}}$

${ }^{1}$ Department of Chemistry, National Chung Hsing University,

Taichung, Taiwan 402, Republic of China.

${ }^{2}$ Department of Applied Chemistry, Sejong University,

Seoul 143-747, Korea. feng64@nchu.edu.tw

Amyloid- $\beta$ peptide (A $\beta$ ) was the principal constituent of plaques and fibrils, commonly believed as the main source of the neurotoxicity associated with Alzheimer's disease (AD). Metal ions have been proposed to play a central role in the $\mathrm{A} \beta$ neurotoxicity, which can be estimated by their oxidation potentials. In this study, we investigate the oxidation potential of the $\mathrm{A} \beta$ peptide and its possible aggregates when binding with various metal ions, such as $\mathrm{Cu}$ and $\mathrm{Zn}$, through ab initio calculation. Several models of copper-A $\beta$ complex were proposed and investigated with ab initio calculation. All structures of metal- $\mathrm{A} \beta$ complexes were optimized at the M052X/LANL2DZ level with the Gaussian 03 suit of program, and a comparison of neurotoxicity among the metal-A $\beta$ complexes and their associated aggregates was proposed.

\section{References}

1. Goate A, Chartier-Harlin M-C, Mullan M, Brown J, Crawford F, Fidani L, Giuffra L, Haynes A, Irving N, James L, Mant R, Newton P, Rooke K, Roques P, Talbot C, Pericak-Vance M, Roses A, Williamson R, Rossor M, Owen M, Hardy J (1991) Nature 349:704 2. Raffa D, Rauk A (2007) J Phys Chem B 111:3789

\section{P711}

A Theoretical study on the structure of copper-binding peptides: implication in the aggregation of $\beta$-amyloid (A $\beta$ ) peptide

Ren-jie Lin ${ }^{1}$, Soomin Jang ${ }^{2}$, Hsiang-ling Wang ${ }^{1}$, Chen-chang $\mathrm{Wu}^{1}$, Feng-Yin $\mathrm{Li}^{1}$

${ }^{1}$ Departemnt of Chemistry, National Chung Hsing University, Taichung, Taiwan 402, Republic of China.

${ }^{2}$ Department of Applied Chemistry, Sejong University, Seoul143-747, Korea. feng64@nchu.edu.tw

As the principal constituent of plaques and fibrils, Amyloid- $\beta$ peptide $(\mathrm{A} \beta)$ was commonly believed to be responsible for the neurotoxicity associated with Alzheimer's disease (AD). Copper has been hypothesized to play an important role in both the $\mathrm{A} \beta$ aggregation and its neruotoxicity. However, the structure of copper $-\mathrm{A} \beta$ complex is still a controversial issue, not mentioned its properties. Several models of copper- $\mathrm{A} \beta$ complex were proposed and investigated with ab initio calculation. All structures of copper-A $\beta$ complexes were optimized at the M052X/LANL2DZ level with the Gaussian 03 suit of program, and an $\mathrm{A} \beta$ aggregation formation mechanism was proposed.

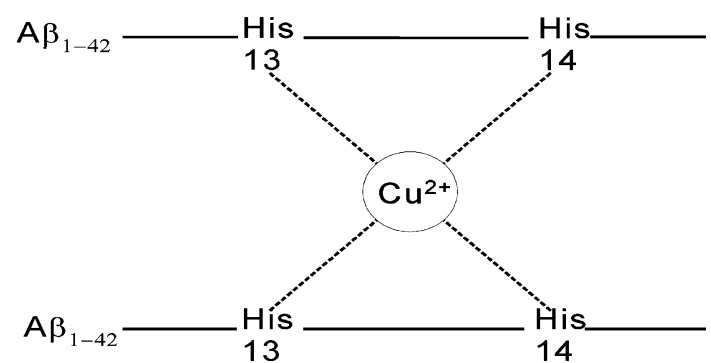

References

1. Goate A, Chartier-Harlin M-C, Mullan M, Brown J, Crawford F, Fidani L, Giuffra L, Haynes A, Irving N, James L, Mant R, Newton P, Rooke K, Roques P, Talbot C, Pericak-Vance M, Roses A, Williamson R, Rossor M, Owen M, Hardy J (1991) Nature 349:704 2. Raffa D, Rauk A (2007) J Phys Chem B 111:3789

\section{P712}

Synthesis of bioorganometallic complex bearing uracil moiety

Toshiyuki Moriuchi, Shunichi Noguchi, Mizuki Abe, Toshikazu Hirao

Department of Applied Chemistry, Graduate School of Engineering, Osaka University, Yamada-oka, Suita, Osaka 565-0871, Japan. hirao@chem.eng.osaka-u.ac.jp; moriuchi@chem.eng.osaka-u.ac.jp Recently, the research field of bioorganometallic chemistry, which is a hybrid area between biochemistry and organometallic chemistry, has received extensive interest. Utilization of self-assembling properties of nucleobases in bio-inspired systems offers the flexibility of 
exploiting different binding motifs. On the other hand, luminescent platinum(II) complexes have attracted attention. In this context, we herein report a combination of luminescent platinum(II) complexes with nucleobases for the development of novel functional bioorganometallic systems. Uracil derivative as a nucleobase moiety and a pincer-type platinum(II) complex as a oraganoplatinum complex are focused on in this project. The Sonogashira coupling of 6-ethynyl-1octyluracil (1) and 4-bromo-3,5-bis (dimethylaminomethyl)iodobenzene (2) by using $\mathrm{Pd}\left(\mathrm{PPh}_{3}\right)_{4}$ as a catalyst afforded the pincer-type ligand 3 bearing the uracil moiety. The pincer-type platinum(II) complex bearing the uracil moiety $\mathbf{4}$ was obtained quantitatively by treatment of $\mathbf{3}$ with $\left[\mathrm{Pt}(p \text {-tolyl })_{2}\left(\mathrm{Et}_{2} \mathrm{~S}\right)\right]_{2}$.
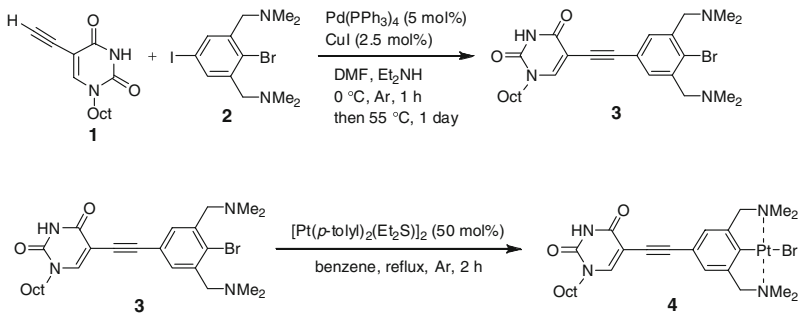

\section{P713}

\section{Ruthenium(II)-arene compounds bearing}

maltol-derived ligands: synthesis, in vitro anticancer activity and mode-of-action studies

\section{Christian G. Hartinger ${ }^{1}$, Wolfgang Kandioller ${ }^{1}$,}

Maria Mendoza-Ferri ${ }^{1}$, Alexey A. Nazarov ${ }^{1,2}$, Paul J. Dyson ${ }^{2}$, Bernhard K. Keppler ${ }^{1}$

${ }^{1}$ University of Vienna, Institute of Inorganic Chemistry, 1090 Vienna, Austria.

${ }^{2}$ Institut des Sciences et Ingénierie Chimiques, Ecole Polytechnique Fédérale de Lausanne (EPFL), 1015 Lausanne, Switzerland.

christian.hartinger@univie.ac.at

Ruthenium compounds are the best developed metal-based nonplatinum anticancer agents, in particular with KP1019 and NAMI-A, two ruthenium(III) compounds, undergoing clinical trials. In recent years, organometallic ruthenium(II)-arene compounds moved into the focus of interest and compounds with activity against primary tumors and antimetastatic activity were reported. The attachment of maltol as ligand to $\mathrm{Ru}(\mathrm{II})$-arene moieties gave compounds which are not active in vitro. However, switching from maltol or other pyrones to pyridinone and thiopyrone ligands resulted in mono- and dinuclear compounds with high in vitro anticancer activity $[1,2]$.

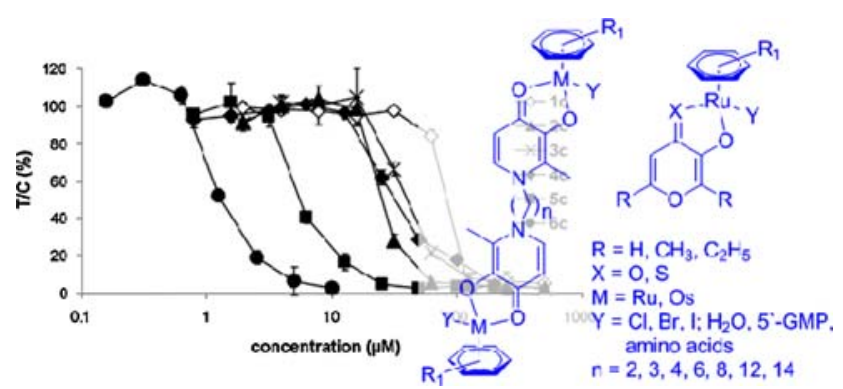

\section{References}

1. Mendoza-Ferri MG, Hartinger CG, Eichinger RE, Stolyarova N, Severin K, Jakupec MA, Nazarov AA, Keppler BK (2008) Organometallics 27:2405-2407

2. Kandioller W, Hartinger CG, Nazarov AA, Kasser J, John Z, Jakupec MA, Arion VB, Dyson PJ, Keppler BK (2009) J Organomet Chem 694:922-929

\section{P714}

Selection of small-molecule-binders for biopolymers from dynamic combinatorial libraries Peter-Korbinian B. C. Müller-Graff ${ }^{1}$, Helga Szelke ${ }^{1}$, Roland Krämer ${ }^{1}$

${ }^{1}$ Department of Inorganic Chemistry, University of Heidelberg, Im Neuenheimer Feld 270, 69120 Heidelberg, Germany.

Korbinian.Mueller-Graff@aci.uni-heidelberg.de

Dynamic combinatorial chemistry (DCC) stands for applying combinatorial chemistry under thermodynamic control. Exposing an equilibrated mixture of different building blocks to an external stimulus (e.g. addition of a biopolymer) allows testing more than just one compound per assay [1].

Here we introduce the DCC of a system containing Fe(II) and bipyridines. Visualizing changes in equilibrium can be realized by adding a competing ligand, dipicolyl-amine (DPA), which binds stronger to $\mathrm{Fe}(\mathrm{II})$ than $\mathbf{1}$ and $\mathbf{2}$ in absence of target. Adding polyanionic heparin to a mixture containing both compounds results in a shift from yellow $\left(\left[\mathrm{Fe}(\mathrm{dpa})_{2}\right]^{2+}\right)$ to red $\left(\left[\mathrm{Fe}(\mathbf{2})_{3}\right]^{5+}\right)$ (Fig. 1).

Very recently we showed a 120 -fold enrichment of complex mer$\mathrm{Fe}(\mathbf{2})_{2}$ in presence of DNA applying reverse phase HPLC (Fig. 2). Our experiments demonstrate an enrichment of the best DNA binder and show the dynamic nature of the process. Additionally we offer a promising exchange labile system required in DCC basing on metalligand coordination.

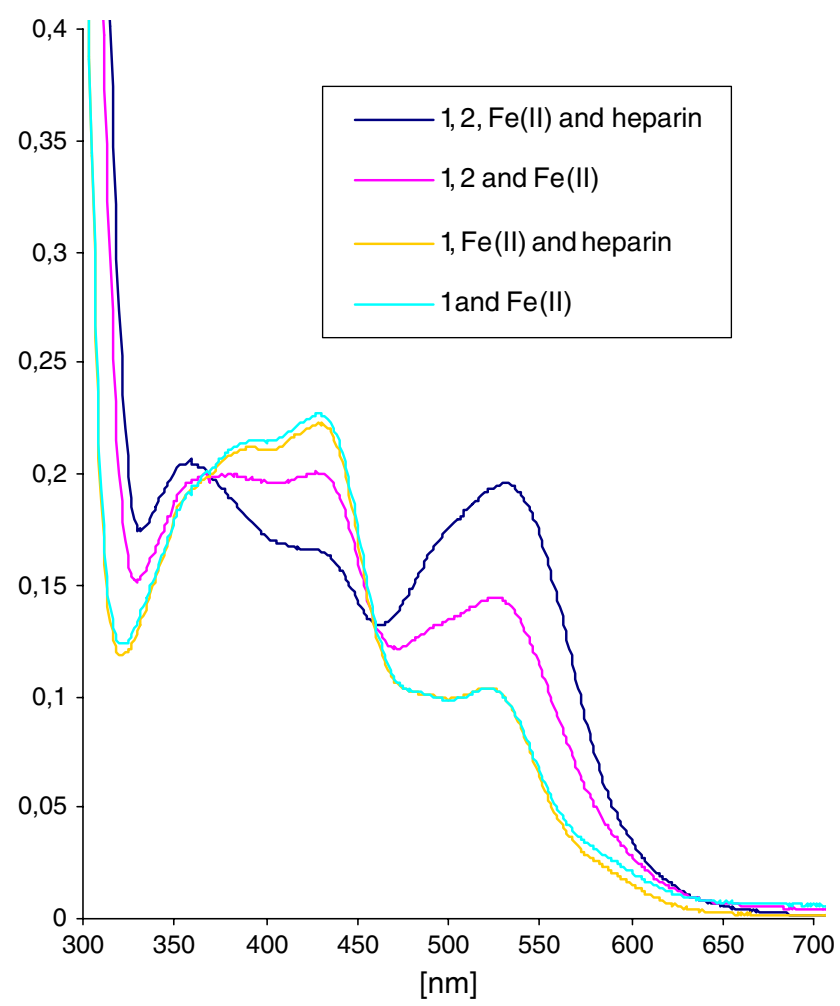

Fig. 1 Enrichment of $\left[\mathrm{Fe}(2)_{3}\right]^{5+}$ by heparin from a DCC containing 1, 2 and $\mathrm{Fe}(\mathrm{II})$ 


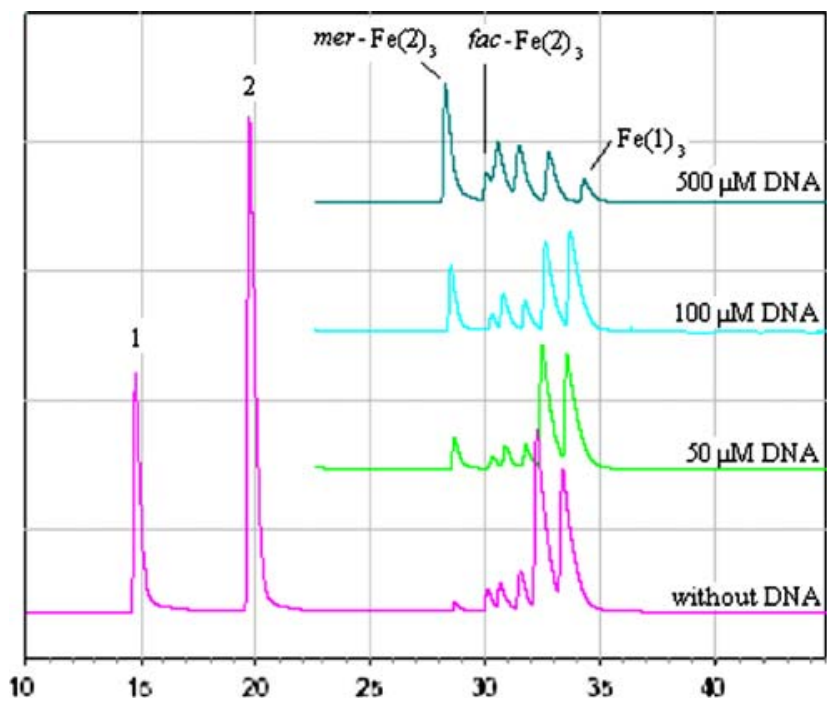

Fig. 2 Reverse phase HPLC of a DCC containing 1, 2 and Fe(II) in presence of DNA
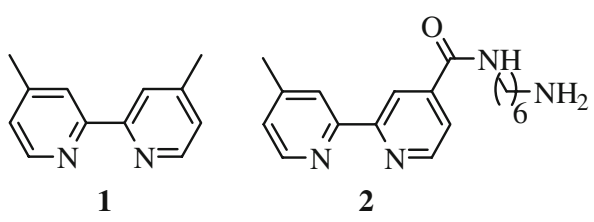

\section{References}

1. Corbett PT, Leclaire J, Vial L, West KR, Vietor J-L, Sanders JKM, Otto S (2006) Chem Rev 106:3652-3711

\section{P715}

\section{Cell uptake and cytotoxicity of metal-peptide- bioconjugates}

\section{A. Groß, N. Metzler-Nolte}

Ruhr-Universität Bochum, Universitätsstr. 150, Bochum, Germany. Annika.Gross@rub.de

Organometallic conjugates of cell-invasive peptides are proposed as interesting candidates for a future generation of novel cancer therapies since they are structurally unique compared to other classes of routinely used cytotoxic drugs. We, therefore, aimed to synthesise various metal compounds linked to peptides. Solid and solution phase methods were used to generate peptides and their fluorescent and metal containing analogs. Cell uptake, and the effect of the metal was investigated by comparison of metallocene-peptide conjugates to acetylated peptides using fluorescence microscopy. Intracellular fate was examined in co-localisation studies using compartment-specific dyes. Cytotoxicity studies of functionalised peptides were performed using the Resazurin and Crystal Violet proliferation assays on different cell lines. Peptides containing acetyl, ferrocene, ruthenocene, cobaltocene and cobalt carbonyl moieties were successfully synthesised, purified and characterised. All bioconjugates were cell permeable and co-localised with a lysosome-specific dye. Metallocene and reference compounds were not toxic in the range 100$1,000 \mu \mathrm{M}$. However, depending on the cell line, the cobalt carbonyl gave $\mathrm{IC}_{50}$ values down to $10 \mu \mathrm{M}$ in these assays. Ferrocene, ruthenocene and cobaltocenium show no cytotoxicity, but cobalt carbonyl renders the conjugate cytotoxic.

\section{P716}

Investigations on the reactivity of $\left[\mathrm{Mn}(\mathrm{CO})_{3}(\mathrm{tpm})\right]^{+}$: a carbonyl complex that exhibits photoinduced cytotoxicity

Johanna Niesel, Hendrik Pfeiffer and Ulrich Schatzschneider* Lehrstuhl für Anorganische Chemie I, Ruhr-Universität Bochum, Universitätsstr. 150, 44801 Bochum, Germany.

johanna.niesel@rub.de

Recently, the manganese tricarbonyl complex $\left[\mathrm{Mn}(\mathrm{CO})_{3}(\mathrm{tpm})\right]^{+}$ $($ tpm $=$ tris(1-pyrazolyl)methane) was shown to exhibit photoinduced cytotoxicity against HT29 human colon cancer cells. To gain insight in the mode of action, product formation of the complex was investigated by UV/Vis spectoscopy and ESI mass spectrometry. The interaction of the complex with amino acids and DNA was examined by ESI mass spectrometry and gel electrophoresis.
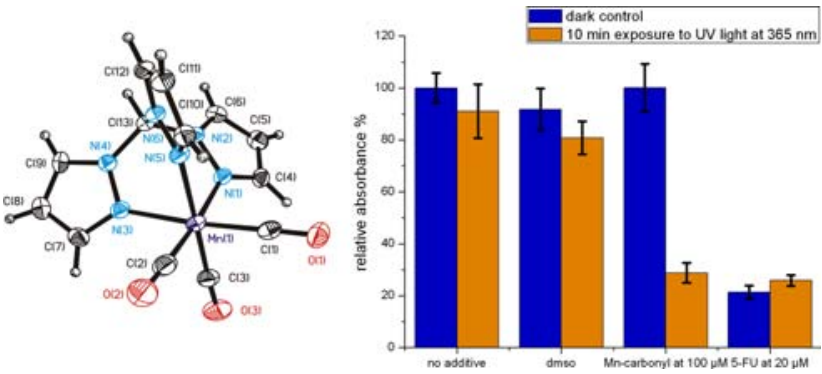

For individual cytotoxicity testing, species that were identified to form upon irradiation as well as further complexes with different ligand systems, anions and centres were synthesized.

\section{References}

1. Niesel J, Pinto A, Peindy N'Dongo HW, Merz K, Ott I, Gust R, Schatzschneider U (2008) Chem Commun 1798-1800

2. Pfeiffer H, Rojas A, Niesel J, Schatzschneider U (2009) Dalton Trans. doi:10.1039/b819091g

\section{P717}

\section{Functionalization of peptides with $\mathrm{CO}$ releasing metal} carbonyl moieties

Hendrik Pfeiffer, Johanna Niesel and Ulrich Schatzschneider*

Lehrstuhl für Anorganische Chemie I, Ruhr-Universität Bochum,

Universitätsstr. 150, D-44801 Bochum, Germany.

hendrik.pfeiffer@rub.de

It is now well-established that carbon monoxide acts as an important small molecule messenger in the human body [1]. Since $\mathrm{CO}$ is a toxic and difficult to dose gas, there is considerable interest in the development of "solid storage forms" for carbon monoxide. Transition metal carbonyl complexes are a natural choice as "CO releasing molecules" (CORMs) [2]. Photoactivated CO release will allow for a precise spatial and temporal control of its biological action. We have recently identified several $\mathrm{M}(\mathrm{CO})_{\mathrm{x}}$ complexes with group VI and VII metals and bidentate as well as tridentate nitrogen donor ligands as promising new CORMs, which release $\mathrm{CO}$ to myoglobin upon irradiation, but are inert in the dark in aqueous solution [3]. Carrier peptides are important vehicles for a targeted cellular delivery of bioactive cargos. Thus, we have explored the functionalization of the parent compounds with model peptides and amino acids using the Pd-catalyzed Sonogashira cross-coupling and the alkyne-azide 1,3-dipolar cycloaddition [4]. Both were found to be fully compatible with all functional groups present. The CORM-peptide conjugates 
were isolated in reasonable yield and high purity. The myoglobin assay was used to demonstrate that they have $\mathrm{CO}$ release properties identical those of the parent compounds.

\section{References}

1. Ryter SW, Alam J, Choi AMK (2006) Physiol Rev 86:583

2. Boczkowski J, Poderoso JJ, Motterlini R (2006) Trends Biochem Sci 31:614

3. Niesel J, Pinto A, Peindy N'Dongo HW, Merz K, Ott I, Gust R, Schatzschneider U (2008) Chem Commun 1798-1800

4. Pfeiffer H, Rojas A, Niesel J, Schatzschneider U (2009) Dalton Trans. doi:10.1039/b819091g.

\section{P718}

\section{Bio-inspired chiral zinc(II) catalysts for enantioselective} aldol reactions

Masanori Kitamura, Susumu Itoh, Shin Aoki

Faculty of Pharmaceutical Sciences, Tokyo University of Science, Noda 278-8510, Japan.masak@rs.noda.tus.ac.jp

Aldolases are enzymes that catalyze stereospecific aldol reactions in a reversible manner. Aldolases in nature are classified into two groups on the basis of reaction mechanisms. Class I aldolases form an enamine intermediate between the lysine residue of the enzyme and the carbonyl group of substrates. On the other hand, class II aldolases use the zinc ion, which acts as a Lewis acid in the active site. In this work, we wish to report on the design and synthesis of novel chiral zinc(II) catalysts (1 and $\mathbf{2}$ ) inspired by class I and II aldolases. The results of the potentiometric $\mathrm{pH}$ titrations of $\mathbf{1}$ and $\mathbf{2}$ and aldol reaction of acetone with 2-chlorobenzaldehyde (3) in the presence of $5 \mathrm{~mol} \%$ catalysts will be presented.
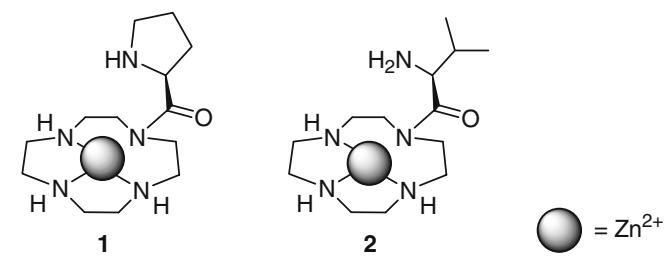<smiles>CC(=O)COC(=O)OC(C)=O</smiles>

3

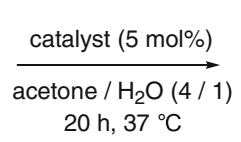

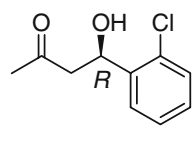

4 up to $87 \%$ yield, $80 \%$ ee

\section{P719}

Structural, spectroscopic, thermal properties of the nickel(II) supramolecule containing the macrocycle and the aromatic ligand

Sol Han ${ }^{1}$, Ju Chang Kim ${ }^{1 *}$

${ }^{1}$ Departent of Chemistry, Pukyong National University, Busan 608-

737, Korea. creat00000@naver.com

Two new nickel(II) complexes with the composition $\left\{\left[\mathrm{Ni}(\mathbf{L})\left(4,4^{\prime}\right.\right.\right.$ bpdc) $\left.] \cdot 3 \mathrm{H}_{2} \mathrm{O}\right\}_{\mathrm{n}}(\mathbf{1})$ and $\{[\mathrm{Ni}(\mathbf{L})(2,6-\mathrm{ndc})] \cdot 2 \mathrm{MeCN}\}_{\mathrm{n}}(\mathbf{2})(\mathbf{L}=1,8$-dihydroxylethyl-1,3,6,8,10,13-hexaazacyclotetradecane, 4,4'-bpdc = 4,4'-biphenyldicarboxylic acid dianion, 2,6-ndc $=2,6$-naphthalenedicarboxylic acid dianion) have been synthesized and structurally characterized by a combination of analytical, spectroscopic, and $\mathrm{X}$-ray crystallography. In the structure of $1,1 \mathrm{D}$ chains are formed by the reaction between $[\mathrm{Ni}(\mathrm{L})] \cdot \mathrm{ClO}_{4}$ and $4,4^{\prime}$-biphenyldicarboxylic acid dianion. They are interconnected as a network fashion with hydrogen bonds between uncoordinated oxygen atom of 4,4'-biphenyldicarboxylic acid and water molecules. In the structure of 2, 1D chains are formed by the reaction between $[\mathrm{Ni}(\mathrm{L})] \cdot \mathrm{ClO}_{4}$ and 2,6-naphthalenedicarboxylic acid dianion. They are interconnected as a zigzag fashion with the hydrogen bonds of the pendant groups and bridging ligands.
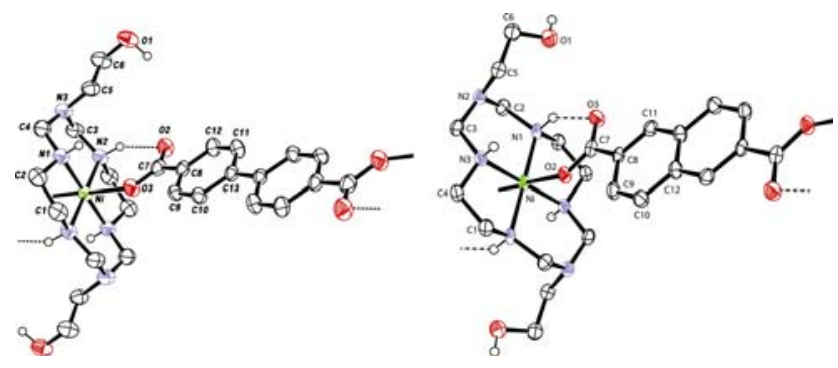

References

1. Min KS, Suh MP (2001) Eur J Inorg Chem 449-455

\section{P720}

1D Zinc(II) coordination polymers containing different 1,1'-ferrocene dicarboxylate conformation Jin Suk Kwag, Ju Chang Kim

Department of Chemistry, Pukyong National University, 599-1

Daeyeon 3-dong, Nam-gu, Busan 608-737, korea. tnr302@gmail.com Two new zinc(II) complexes of composition $\left\{\left[\mathrm{Zn}(\mathrm{L} 1)\left(\mathrm{Fe}\left(\eta^{5}-\mathrm{C}_{5} \mathrm{H}_{4}\right.\right.\right.\right.$ $\left.\left.\left.\mathrm{COO})_{2}\right)\right] \cdot 3 \mathrm{H}_{2} \mathrm{O}\right\}_{n}, \mathbf{1}$, and $\left\{\left[\mathrm{Zn}(\mathrm{L} 1)\left(\mathrm{Fe}\left(\eta^{5}-\mathrm{C}_{5} \mathrm{H}_{4} \mathrm{COO}\right)_{2}\right)\right] \cdot 2 \mathrm{H}_{2} \mathrm{O}\right\}_{n}, \mathbf{2}$, have been prepared and fully characterized. The orange complexes 1 and 2 consist of 1D polymeric chains with zinc(II) macrocycles and bridging $1,1^{\prime}$-ferrocene dicarboxylate ligands. The structural difference between the comformations of the macrocycles L1 and L2 induces transformation of $1,1^{\prime}$-ferrocene dicarboxylate conformation. In molecule 1 , the two $\mathrm{Cp}$ rings of $1,1^{\prime}$-ferrocene dicarboxylate are staggered conformation. On the other hand, in molecule 2, the two $\mathrm{Cp}$ rings of $1,1^{\prime}$-ferrocene dicarboxylate are almost eclipsed conformation.

\section{References}

1. Kim JA, Park H, Kim JC, Lough AJ, Pyun SY, Roh J, Lee BM (2008) Inorg Chim Acta 361:2087-1093

2. Park H, Kim JC, Lough AJ, Lee BM (2007) Inorg Chem Commun 10:303

\section{P721}

$\mathrm{Ru}^{\mathrm{II}}$ arene anticancer complexes with redox-active diamine ligands

Abraha Habtemariam ${ }^{1}$, Tijana Bugarcic ${ }^{1,2}$, Robert J. Deeth ${ }^{1}$, Simon Parsons $^{2}$ and Peter J. Sadler ${ }^{1}$

${ }^{1}$ Department of Chemistry, University of Warwick, Coventry CV4

7AL, UK. ${ }^{2}$ School of Chemistry, University of Edinburgh,

West Mains Road, Edinburgh EH9 3JJ, UK.

a.habtemariam@warwick.ac.uk

Organometallic half-sandwich $\mathrm{Ru}^{\mathrm{II}}$ arene complexes exhibit anticancer activity in vitro and in vivo [1]. Complexes of the type [ $\left(\eta^{6}-\right.$ arene $\left.) \mathrm{Ru}^{\mathrm{II}}(\mathrm{o}-\mathrm{pda}) \mathrm{Cl}\right]^{+}, \quad$ o-pda $=$ o-phenylenediamine, show good activity towards cancer cells including a lack of cross-resistance with adriamycin (doxorubicin) unlike the ethylenediamine analogue [2]. The synthesis and characterization of $\mathrm{Ru}^{\mathrm{II}}$ arene complexes of the general formula $\left[\left(\eta^{6} \text {-arene }\right) \mathrm{Ru}(\mathrm{YZ})(\mathrm{X})\right]^{+}$, where arene $=$ p-cymene (p-cym), hexamethylbenzene (hmb) and biphenyl (bip), $\mathrm{YZ}=$ (o-pda), o-benzoquinonediimine (o-bqdi) and 4,5-dimethylo-phenylenediamine (dmpda) and $X=\mathrm{Cl}, \mathrm{Br}$ and $\mathrm{I}$, will be 
discussed, including the $\mathrm{X}$-ray structures of $\left[\left(\eta^{6}-\mathrm{p}-\mathrm{cym}\right) \mathrm{Ru}\right.$ (o-pda)Cl] $\left[\mathrm{PF}_{6}\right]$ (1) and $\left[\left(\eta^{6}-\mathrm{hmb}\right) \mathrm{Ru}(\mathrm{o}-\mathrm{bqdi}) \mathrm{Cl}\right]\left[\mathrm{PF}_{6}\right]$ (2). Complex 1 undergoes ligand-based oxidation in methanol, concurrent hydrolysis in water, and exhibits significant cytotoxicity $\left(\mathrm{IC}_{50}=11 \mu \mathrm{M}\right)$, towards A2780 cells, in contrast to the diimine complex $2\left(\mathrm{IC}_{50}>50 \mu \mathrm{M}\right)$. In the presence of $15 \mathrm{~mol}$ equiv GSH, [ $\left(\eta^{6}-\mathrm{p}\right.$-cym $\left.) \mathrm{Ru}(\mathrm{o}-\mathrm{bqdi}) \mathrm{I}\right]\left[\mathrm{PF}_{6}\right]$ underwent ligand-based reduction to give $\left[\left(\eta^{6}-\mathrm{p}-\mathrm{cym}\right) \mathrm{Ru}(\mathrm{o}-\mathrm{pda}) \mathrm{I}\right]\left[\mathrm{PF}_{6}\right]$. Density functional theory (DFT) methods were used to optimize geometries and calculate bonding energies of 9-EtG in the 9-EtG adducts of 1 and 2. We thank Oncosense Ltd for cytotoxicity tests, and members of COST Action D39 for discussion.

\section{References}

1. Yan YK, Melchart M, Habtemariam A, Sadler PJ (2005) Chem Commun 4764-4776

2. Habtemariam A, Melchart M, Fernandez R, Parsons S, Oswald I, Parkin A, Fabbiani FA, Davidson JE, Dawson A, Aird RE, Jodrell DI, Sadler PJ (2006) J Med Chem 49:6858-6868

\section{P722}

\section{Arene-controlled binding of organoruthenium} anticancer complexes to albumin and Ru-induced oxidation of Cys34 Thiol

\section{Fuyi Wang', Wenbing $\mathrm{Hu}^{1}$, Qun $\mathrm{Luo}^{1}$, Xiaoyan Ma ${ }^{1}$,} Jianping Wang ${ }^{1}$, Peter J. Sadler ${ }^{2}$

${ }^{1}$ Institute of Chemistry, The Chinese Academy of Sciences, 100190 Beijing, China. ${ }^{2}$ Department of Chemistry, University of Warwick, Gibbet Hill Road, Coventry CV4 7AL, UK. fuyi.wang@iccas.ac.cn Human serum albumin (HSA) is the most abundant protein in blood and plays a central role in the metabolism of a wide range of drugs, including metallodrugs [1]. Any intravenously-injected metallodrug is likely to interact with this protein, and such binding may have a crucial effect on its bioavailability and toxicology [2]. Here we have studied the interactions of organometallic ruthenium anticancer complexes $\left[\eta^{6}\right.$-arene $\left.) \mathrm{Ru}(\mathrm{en}) \mathrm{Cl}\right] \mathrm{PF}_{6}$, arene $=p$-cymene or biphenyl with recombinant human albumin (rHA). The bottom-up MS analysis revealed that both complexes bound to surface histidine (His128, His247, His510) and methionine (Met298) residues in albumin, but only the $p$-cymene complex can gain entry to the crevice containing the free cysteine thiol group (Cys34) and induce oxidation of thiolate to sulfinate, implying that the nature of the arene ligands can control reactions with Cys34 and subsequently influence the ability of half-sandwich ruthenium arene complexes to induce oxidation of Cys34.
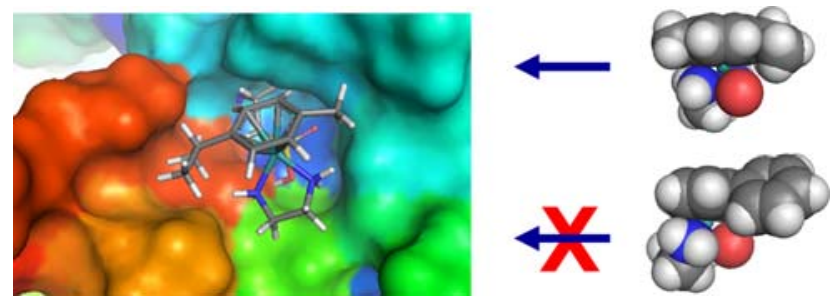

We thank the NSFC (Grant Nos: 20773136, 90713020), the 973 Program (No: 2007CB935601) and the Chinese Academy of Sciences (Hundred Talents Program) for support.

\section{References}

1. Carter DC, Ho JX (1994) Adv Protein Chem 45:153-203

2. Esposito P, Najjar R (2002) Coord Chem Rev 232:137-149

\section{P723}

On the medicinal chemistry of a gold phosphine complex containing a naphthalimide ligand

Ingo Ott

Institute of Pharmaceutical Chemistry, Technische Universität Braunschweig, Beethovenstr. 55, 38106 Braunschweig, Germany. ingo.ott@tu-bs.de

Gold phosphine complexes have recently gained attention due to their strong antiproliferative and antimitochondrial effects, which are most probably related to the irreversible inhibition of the enzyme thioredoxin reductase (TrxR). The mode of action of the compounds is related to the binding of the gold central atom to cysteine and selenocysteine residues of the active site of the enzyme under loss of the coordinated ligands. Novel ligands for gold phosphine complexes with "intrinsic" bioactivity might lead to agents which exhibit multiple properties relevant in antitumor drug design. In this report we describe the design and primary biological evaluation of a luminescent gold phosphine complex containing a naphthalimide ligand (see Fig. 1). Results concerning the antiproliferative properties, induction of apoptosis, inhibition of TrxR, cellular biodistribution and angiogenesis inhibition of the compound will be presented [1].

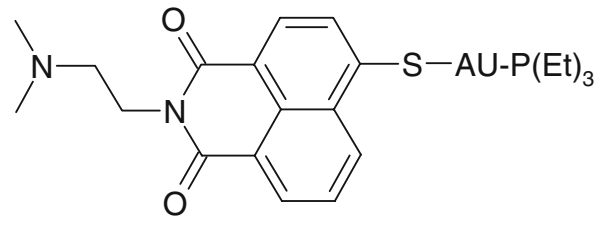

Fig. 1

References

1. Ott I, Qian X, Xu Y, Vlecken DHW, Marques IJ, Kubutat D, Will J, Sheldrick WS, Jesse P, Prokop A, Bagowski CP (2009) J Med Chem $52: 763-770$

\section{P724}

\section{DFT Study on Co-C bond cleavage and hydrogen} transfer in $B_{12}$-dependent enzymes

Takashi Kamachi $^{1}$, Pawel M. Kozlowski ${ }^{2}$, Tetsuo Toraya ${ }^{3}$, Kazunari Yoshizawa ${ }^{1}$

${ }^{1}$ Institute for Materials Chemistry and Engineering, Fukuoka, Japan. ${ }^{2}$ Department of Chemistry, University of Louisville, Louisville, KY, USA. ${ }^{3}$ Department of Bioscience and Biotechnology, Okayama,

Japan.kama@ms.ifoc.kyushu-u.ac.jp

The origin of the enormous catalytic activity of coenzyme B12dependent enzymes continues to be an outstanding problem in bioinorganic chemistry. During enzymatic catalysis the $\mathrm{Co}-\mathrm{C}$ bond of coenzyme B12 (AdoCbl) is cleaved homolytically, leading to the formation of the $5^{\prime}$-deoxyadenosyl radical and cob(II)alamin. The rate of enzymatically accelerated homolytic cobalt-carbon bond cleavage of AdoCbl exceeds the rate observed in aqueous solution by about 12 orders of magnitude as a consequence of the coenzyme interaction with the substrate in the presence of apoenzyme. Despite the great effort that has been devoted to this problem, the mechanism of the catalytic activation is poorly understood. We applied DFT to investigate the initial step of the $\mathrm{Co}-\mathrm{C}$ bond cleavage and possible stabilization of substrate radical by cob(II)alamin. Two mechanisms 


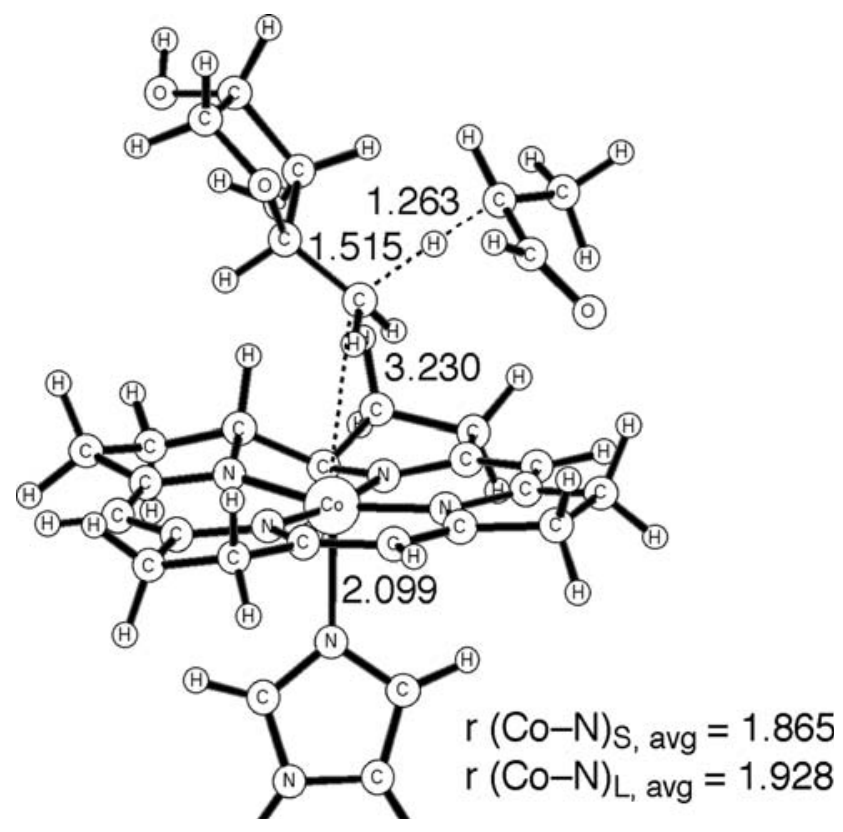

Fig. 1 Optimized structure of the transition state for the concerted pathway

were investigated: concerted and stepwise. It was found that the concerted pathway is energetically lower and leads to substrate radical stabilization by $7 \mathrm{kcal} / \mathrm{mol}$ (Fig. 1). This effect is due to lowering of transition state energy associated with hydrogen abstraction by presence of the corrin ring.

\section{References}

1. Kozlowski PM, Kamachi T, Toraya T, Yoshizawa K (2007) Angew Chem Int Ed 46:980

\section{P725}

\section{Biomimetic iron carbonyl thiolate complexes related}

\section{to the active site of Fe-only hydrogenases}

Yu-Chiao Liu ${ }^{1}$, Shu-Ting Yang ${ }^{1}$, Gene-Hsiang Lee ${ }^{2}$, Ming-Hsi Chiang*1

${ }^{1}$ Institute of Chemistry, Academia Sinica, Nankang, Taipei 115,

Taiwan. ${ }^{2}$ Instrumentation Center, National Taiwan University,

Taipei 106, Taiwan. mhchiang@chem.sinica.edu.tw

A series of iron carbonyl azadithiolates were synthesized to mimic Fe-only hydrogenases. Complexes $\left[\mathrm{Fe}_{2}(\mu-\mathrm{S} \sim \mathrm{S})_{2}(\mathrm{CO})_{6}\right]_{2} \quad$ (1) ( $\mathrm{S} \sim \mathrm{S}=$ diethylthiolate amines) were isolated from reactions of corresponding azadithiolates with triiron dodecacarbonyl. Their structures were characterized by X-ray crystallography, which revealed that two dimeric units were connected by two azadithiolates bridges. ${ }^{1} \mathrm{H}$ and ${ }^{13} \mathrm{C}$ NMR spectroscopy indicated that stereochemical protons of the thiolate bridges and CO ligands of the model complexes are distinguishable on the NMR time scale below $183 \mathrm{~K}$. Treatment of 1 with $\mathrm{PR}_{3}$ led to $\mathrm{CO}$ substitution products $\left[\mathrm{Fe}_{2}\right.$ $\left.(\mu-\mathrm{S} \sim \mathrm{S})_{2}(\mathrm{CO})_{6-x}\left(\mathrm{PR}_{3}\right)_{\mathrm{x}}\right]_{2}(x=1, \mathrm{R}=\mathrm{Ph}, 2 ; x=2, \mathrm{R}=\mathrm{Me}, \mathbf{3})$. Cyanide substituted complexes could be obtained upon reaction of $\mathrm{Et}_{4} \mathrm{NCN}$. Reaction of $\mathbf{1}$ with acids gave stable protonated species $\mathbf{1 H}_{\mathbf{2}}^{\mathbf{2 +}}$. Acidic reaction of $\mathbf{3}$ gave a doubly protonated product first where the $\mathrm{N}$ atoms of azadithiolates were bound with $\mathrm{H}^{+}$. Further reaction with acid led to proton insertion to the $\mathrm{Fe}-\mathrm{Fe}$ bond, forming iron bridging hydride species. Electrochemical study shows that reduction of $\mathbf{3 H}_{\mathbf{4}}^{\mathbf{4 +}}$ gave $\mathrm{H}_{2}$ and $\mathbf{3}$.

\section{P726}

Synthesis and insulin-mimetic activities of zinc(II) complexes with ethyl 2,5-dihydro-4-hydroxy-5-oxo-1 Hpyrrole-3-carboxylates

Ryota Saito $^{1}$, Hikaru Kawarada ${ }^{1}$, Yutaka Yoshikawa ${ }^{2}$, Hiroyuki Yasui $^{2}$

${ }^{1}$ Department of Chemistry, Facult. Sci. Toho University, Chiba 274-8510, Japan. ${ }^{2}$ Department of Analytical and Bioinorganic Chemistry, Kyoto Pharmaceutical University, Kyoto 607-8414,

Japan.saito@chem.sci.toho-u.ac.jp

Zinc(II) ion has attracted increasing attention of medicinal chemists because of its insulin-mimetic activity. Recently, many organozinc complexes with heterocyclic compounds as ligands have been synthesized to exhibit higher insulin-mimetic activities than the inorganic $\mathrm{ZnSO}_{4}$. The role of the heterocyclic ligands is enhancement of the gastrointestinal absorptivity of zinc(II) ion, and, therefore, the ligands become unnecessaries after the absorption. On the other hand, 1(arylmethyl)-2,5-dihydro-4-hydroxy-5- oxo- $1 \mathrm{H}$-pyrrol-3-carboxylates (1) are known as potential drugs for diabetic complications. Although they have metal-chelatable oxygen atoms, no attempt to prepare zinc(II) complexes with 1 (2) have been performed. Thus, we have synthesized the zinc(II) complexes (2) and evaluated their insulin-mimetic activity in order to develop new chemotherapeutics having dual effectives against diabetes mellitus and diabetic complications. From $\mathrm{IC}_{50}$ values, which is a $50 \%$ inhibition concentration of free fatty acid release from the epinephrine-stimulated rat adipocytes, it was found that the zinc(II) complexes (2) showed higher insulin-mimetic activities $\left(\mathrm{IC}_{50}=0.26\right.$ $0.82 \mathrm{mM})$ than $\mathrm{ZnSO}_{4}\left(\mathrm{IC}_{50}=0.7-1.0 \mathrm{mM}\right)[1,2]$. The crystal structure and hydrophobicity of $\mathbf{2}$ will be also reported.

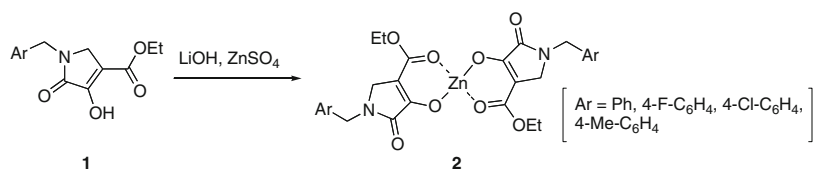

References

1. Adachi $Y$ et al (2004) J Biol Inorg Chem 9:885-893

2. Yamaguchi M et al (2006) J Inorg Biochem 100:260-269

\section{P727}

\section{Novel metal-based imidazolyl pyrazole Cdk inhibitors} for anticancer therapy

\section{N. Stepanenko, V. B. Arion, B. K. Keppler}

Institute of Inorganic Chemistry, University of Vienna, Währingerstr. 42,1090Vienna, Austria. iryna.stepanenko@univie.ac.at

The main targets in cancer chemotherapy which leads to suppression of tumour growth are DNA itself or cyclin-dependent kinases (Cdks), responsible for DNA replication and the cell cycle regulation. The observed synergy of some Cdk inhibitors with platinum complexes under drug combination therapy permits to suppose preserving or even enhancing after complexation their antitumour and $\mathrm{Cdk}$ inhibiting activity. The metalation of paullones (Cdk inhibitors) resulted in sufficient aqueous solubility and bioavailability of paullones, making them potentially usable for medical application. The present work is focusing on the investigation of the metalation effect on the biological properties of some potent imidazolyl pyrazole $\mathrm{Cdk}$ inhibitors and antiproliferative agents. Their organometallic complexes $\left[\mathrm{MCl}\left(\eta^{6}-p\right.\right.$-cymene $\left.) \mathrm{L}\right] \mathrm{Cl}$ (where $\mathrm{M}=\mathrm{Ru}, \mathrm{Os} ; \mathrm{L}=$ imidazolyl pyrazoles) as new potent antitumour drug candidates are now under investigation. These compounds were characterized by NMR, IR, UV-vis spectroscopy, ESI mass spectrometry, and $\mathrm{X}$-ray crystallography. The elucidation of the roles of both the metal and ligands in the mechanism of their antiproliferative activity is in progress. 